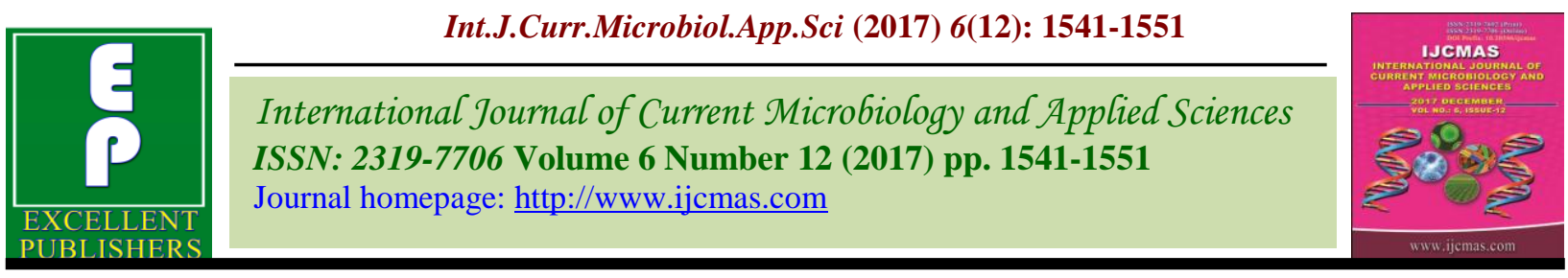

Review Article

https://doi.org/10.20546/ijcmas.2017.612.172

\title{
Prospectus of use of Nanotechnology in Agriculture-A Review
}

\author{
M. Banotra ${ }^{*}$, A. Kumar, B.C. Sharma, B. Nandan, A. Verma, R. Kumar, \\ V. Gupta and S. Bhagat
}

Division of Agronomy, SKUAST Jammu, Chatha, India

*Corresponding author

\begin{tabular}{|c|c|}
\hline \multicolumn{2}{|r|}{ A B S T R A C T } \\
\hline & \multirow{6}{*}{$\begin{array}{l}\text { In modern era large amount of fertilizers, pesticides, herbicides are used in crops to } \\
\text { achieve more production per unit area but using more dose than the optimum of these } \\
\text { chemicals and fertilizers lead to several problems like environment pollution (soil, water } \\
\text { and air), low input use efficiency, degrade the quality of produce, develop resistant to } \\
\text { weeds, disease insect and pest, degrade the soil, causes deficiency of micronutrients in soil, } \\
\text { toxicity to different beneficial living microorganism present above and below the soil etc. } \\
\text { Excessive use of fertilizers, pesticides and insecticides also caused several health issues in } \\
\text { population. Despite these problems there is also challenge to feed the growing population } \\
\text { of country. Therefore in future, there is need to produce nutritive agricultural produce rich } \\
\text { in protein and other essential nutrient required to the human and animal consumption that } \\
\text { is why emphasis should be laid on production of high quality food with required quantity } \\
\text { of nutrients and proteins. For solving these problems in crop production Nano-fertilizers, } \\
\text { pesticides may be the effective tools in agriculture for better pest and nutrient management } \\
\text { (Jyothi and Hebsur, 2017). }\end{array}$} \\
\hline Keywords & \\
\hline & \\
\hline Article Info & \\
\hline $\begin{array}{l}\text { Accepted: } \\
\text { 12 October } 2017 \\
\text { Available Online: } \\
10 \text { December } 2017\end{array}$ & \\
\hline & \\
\hline
\end{tabular}

\section{Introduction}

\section{Nanotechnology and agriculture}

The word "Nanotechnology" has originated from a Greek word "Nanos" which means "Dwarf". The term "Nanotechnology" was first used by Norio Taniguchi in 1947. (EPA, 2017).Nanotechnology is providing different Nano devices and Nano material which have a unique role in Agriculture such as Nano bio sensors to detect moisture content and nutrient status in the soil and also for site specific water and nutrient management, Nano fertilizers for efficient nutrient management, Nano fertilizers for efficient nutrient management, Nano fertilizers for effective weed control in crop field, Nano particles to increase seed vigour, Nano pesticides for efficient pest management. Nano pesticide can be used for efficient nutrient management, Nano particles can be also used as herbicide carrier material especially for herbicide such as Paraquat (Silva et al., 2011). Nano particles are effective in weed management (Chinnamuttu and Kokiladevi, 2007). Hence Nanotechnology have greater role in crop production with environmental safety, ecological sustainability and economic 
stability. The Nano particles produced with the help of nanotechnology can be exploited in the value chain of entire agriculture production system (Tarafdar et al., 2012). Nanotechnology as a powerful new technology has the ability to create a great revolution and transformation in food supply system in global scope (Mir et al., 2015).

The Nano-Particles have the following properties

Nano particle has small size; there are more atoms on the surface of Nano-particle as compared to the interior of the Nano-particles. This leads to the larger surface to volume ratio which in turn leads to higher charge density and higher reactivity of Nanoparticles.

Nano-particle have high surface area in comparison to volume, the behaviour of the atoms on the surface of particles becomes more than the inside the particles. Once the particles becomes small enough they exhibit quantum mechanical behaviour

Due to large surface to volume ratio there is more interaction between atoms, when intermixed with material in Nano-particles, which leads to increased strength, increased heat resistance and decreased melting point.

Nano-particle have higher catalytic activity when they are present in tetrahedral structure followed by cubic and spherical structure followed by cubic and spherical structure attributed to enhancement of chemical reactivity at the sharp edges of the corner at the former.

The different Nano-particles except hydroxyl apatite, have Zeta potential in between +30 and $-30 \mathrm{mv}$ and show high tendency to agglomerate to higher particle sizes (Adhikari et al., 2010). Nanoparticles can have varied compositions, from being composed of metal oxide, ceramics, silicates, magnetic materials, quantum dots, lipid polymers and dendrimers to emulsion. For example, polymer coated Nano fertilizers are used as agrochemical carrier due to its controlled release ability, where metal Nano particles show size dependant properties such as magnetism, fluorescence, photo catalytic degradation which have application in sensor development, agrochemical degradation and soil remediation (Ghormade et al., 2011).

\section{Nano fertilizers}

Nano-fertilizers are synthesized or modified form of traditional fertilizers, fertilizers bulk materials or extracted from different vegetative or reproductive parts of the plant by different chemical, physical, mechanical or biological methods with the help of Nanotechnology used to improve soil fertility, productivity and quality of agriculture produces. Nano particles can be made from fully bulky materials (Brunnert et al., 2006). Coating and binding of nano and sub nano composites are able to regulate the release of nutrients from the fertilizer capsule (Naderi et al., 2013).

At Nano scale physical and chemical properties are differing than bulky material (Nel et al., 2006). Rock phosphate if use as nano form it may increase availability of phosphorus to the plant because direct application of rock phosphate nano-particles on the crop may prevent fixation in the soil. Similarly there is no iron and calcium fixation of the phosphorus, hence it increase phosphorus availability to the crop plant. The use of Nano fertilizers release nutrients for precise control can be effective step towards achieving sustainable Agriculture and compatible with the environment. Iron chelated Nano fertilizer can be considered as a rich reliable source of bivalent iron for plant 
because of its high stability and gradual release of iron with wide $\mathrm{Ph}$ range (7-11). One advantage of this Nano fertilizer is using no ethylene compounds in its structure. Ethylene enhances growth process and prevents appearing indications caused by chlorosis in leaves (Monsef-Afshar et al., 2013). Iron is critical for chlorophyll formation and photosynthesis and is important in enzyme systems and respiration of plants (Nandi et al., 2013).

Using Nano-fertilizer for control of nutrient release could be considered as an effective way to achieving sustainable agriculture and Environment. Some soluble phosphate salts, heavily used in agriculture as highly effective phosphorus (P) fertilizers, causing surface water eutrophication, while solid phosphates are less effective in supplying the nutrient $\mathrm{P}$. In contrast, synthetic apatite Nano-particles could hypothetically supply sufficient $\mathrm{P}$ nutrients to crops but with less mobility in the environment and with less bio available $\mathrm{P}$ to algae in comparison to the soluble counterparts. Nano-fertilizer application on the growth of soybean, enhancement of the growth rate and seed yield was reported with the application of Nano-apatite fertilizer as $\mathrm{P}$ source compared with conventional fertilizer treatment.

\section{Conventional fertilizer versus nanofertilizers}

Conventional fertilizers are generally applied on the crops by either spraying or broadcasting. One of the major factor that decide the mode of application is the final concentration is the final concentration of the fertilizers reaching to the plant but in actual very less concentration of (much below to minimum desired concentration) reaches the desired concentration) reaches to the targeted site due to leaching of chemicals, drift runoff, evaporation, hydrolysis by soil moisture and photolytic and microbial degradation. It has been estimated that around 40-70 \% of nitrogen, $80-90 \%$ of Phosphorus and $50-90 \%$ of potassium content of applied fertilizer are lost in the environment and couldn't reach the plant which causes the sustainable and economic losses (Ombodi and Saigusa, 2000). These problems have initiated repeated use of fertilizer and pesticide which adversely affects the inherent nutrient balance of the soil but the large scale use of chemical fertilizers and pesticides has resulted in environmental pollution affecting flora and fauna. Tilman et al., (2002) reported that excess use of fertilizers reduces soil micro-flora diminishes nitrogen-fixation. Hence, it is important to optimize the use of chemical fertilization to full fill the crop nutrient requirements and to minimize the risk of environmental pollution. Therefore, it is necessary to test the other methods to provide the necessary nutrients for the plant growth and yield production, while keeping the soil structure in the good shape and environment clean (Miransari, 2011).

Nanotechnology has provided the feasibility of exploring the nano scale or nano structured materials as a fertilizer carrier or controlled release vector for building of the so-called smart fertilizers as new facilities to enhance the nutrient use efficiency and reduce the cost of environmental pollution (Chinnamuth and Boopati, 2009). A nano fertilizer refers to a product in nano meter in nano meter regime that delivers nutrient to the crops. For, example encapsulation, inside nano materials coated with a thin protective polymer film or in the form of particles or emulsions of nano scale dimensions. Surface coating of nano materials on fertilizer particles hold the material the hold the material more strongly due to the surface tension than the conventional surfaces and thus helped in the controlled release (Brady and Weil, 1999). Delivery of agrochemical substance such as fertilizer supplying macro and micronutrients 
to the plant is an important aspect of application of Nanotechnology in agriculture. Nano-fertilizer had controlled release of agrochemicals, site targeted delivery, reduction in toxicity and enhanced nutrient utilization of delivered fertilizers (Cui et al., 2010). These attributes of Nanoparticles are due to their high surface area to volume ratio, high solubility and specific targeting due to small size, high mobility and low toxicity (Sasson et al., 2007).

\section{Advantage of nano fertilizers over commercial fertilizers}

Nanofertilizers are advantageous over conventional fertilizers as they increase the soil fertility, yield and quality parameters of the crop, they are non-toxic and less harmful to the humans, they minimize the cost and maximize the profit.

Nanoparticles increase the nutrient use efficiency of the crop and minimizing the cost of environment protection.

Nanoparticles cause improvement in the nutritional content of the crops and the quality of the taste.

Enhance plant growth by resisting diseases and improving stability of the plants by antibending and deeper rooting of the crops (Singh et al., 2017).

\section{Nano-fertilizer formulations and their smart delivery system}

The formulation of any nano fertilizer should be in such a way that they possess all desired properties such as high solubility, stability, effectiveness, time controlled release, enhanced targeted activity with effective concentration and less eco toxicity with safe, easy mode of delivery and disposal (Torney et al., 2007). Nanoparticles have a great potential to deliver nutrients to specific target sites in the living systems. The loading of nutrients on the nano particles is usually done by (a) absorption of nano particles (b) attachment of nano particles mediated by ligands (c) encapsulation in nano particulate polymeric shell (d) entrapment of polymeric nano particles and (e) Synthesis of nano particles composed of the nutrient itself.

Corradini et al., (2010) evaluated the interaction and stability of chitosan nano particles suspensions containing $\mathrm{N}, \mathrm{P}$ and $\mathrm{K}$ fertilizers which can be useful of agricultural applications where as Kottegoda et al., (2011) synthesised urea modified hydroxyapatite (HP) nano particles for gradual release of nitrogen with the crop growth. These nano fertilizers show the initial burst and subsequently slow release of nitrogen up to 60 days of plant growth compared to commercial fertilizer which shows release only up to 30 days. The large surface area of HA facilitates the large amount of urea attachment on the $\mathrm{Ha}$ surface. Strong interaction between HA nano particles and urea contributes to the slow and controlled release of urea. Similarly nano based mesoporous nano particles can also provide efficient carrier system to agrochemical compounds which improves the efficiency and economical utilization. Mesoporous Silica nano particles (150nm) have been reported to entrap urea. It has been observed that $15.5 \%$ of urea was loaded inside the nano particles pores and demonstrated a controlled urea release profile in soil and water. Zinc solubility and dissolution kinetics of $\mathrm{ZnO}$ nano particles and bulk $\mathrm{ZnO}$ particles coated on macronutrient fertilizers (Urea and mono ammonium phosphate) have been compared by Milani et al., (2012). They reported that the coated mono ammonium phosphate granules show faster dissolution rate. The mode of fertilizer application influences the efficiency and impact on plant systems. The following 
methods can be used for nano fertilizer delivery to plant systems.

\section{Aeroponics}

In this method the roots of plant are suspended in air and the nutrient solution is sprayed continuously. In this method, the gaseous environment around the roots can be controlled. However, it requires a high level of nutrients to sustain rapid plant growth, so the use of Aeroponics is not widespread. The method was first introduced by Weathers and Zobel (1992).

\section{Hydroponics}

This method was introduced by Gericke (1937) for dissolved inorganic salts. The method is also commonly known as "Solution culture" as the plants are grown with their roots immersed in a liquid nutrient solution (without soil). Volumes of nutrient solution, maintenance of oxygen demands and $\mathrm{pH}$ are factor that need attention while using this method of nutrient delivery. Supporting materials (sand, gravel etc) are also employed in certain commercial application. In this case the nutrient solution is flushed from one end and old solution is removed from the other end. The disadvantage with this method is frequent pathogen attack and high moisture rates which cause over wilting of soil based plants.

\section{Soil application}

Soil application is the, most common method of nutrient supplement using chemical and organic fertilizers. The factors that need attention while choosing this method of fertilizer applications are how long the fertilizer will last in the soil, soil texture, soil salinity and plant sensitive's to salts, salt content and $\mathrm{pH}$ of the amendment. It is well known that the negative soil particles affect the adsorption of mineral nutrients. The anion exchange capacity of the most agricultural soils is small compared to exchange capacity. Among anions, nitrate remains mobile in the soil solution and is susceptible to leaching by water moving through the soil. Phosphate ions binds to soil particles containing aluminium or iron because the positively charged $\mathrm{Fe}^{2+}, \mathrm{Fe}^{3+}$ and $\mathrm{Al} 3+$ have $\mathrm{OH}-$ group that exchange with phosphate. As a result, phosphate can be tightly bound, and its mobility and availability in soil can limit plant growth (Taiz and Zeiger, 2010).

\section{Foliar application}

Liquid fertilizers are directly sprayed on to leaves. It is generally used for the supply of trace elements. Foliar application can reduce the time lag between application and uptake by plant during the rapid growth phase. It can also circumvent the problem of restricted uptake of a nutrient from soil. Uptake of iron, manganese and copper may be more efficient with this method as compared to soil application where they get absorbed on soil particles and hence are less available to the root system (Taiz and Zeiger, 2010). As stomata and leaf epidermal cells are majorly involved in nutrient uptake, foliar application method can have agronomic advantage if used for nano fertilizer. However, damage to the leaves must be minimized in such cases by standardization of application of protocol. The shortcomings of this method include specific time (morning and evening) of spraying because the stomata open during these time periods only. Another disadvantage is the possibility of plant damage if correct concentration of chemical (fertilizer) is not applied.

\section{Nano particles and plant}

The Nano particles enter the plant root system through the lateral root junctions and reach 
the xylem through the cortex and the pericycle. The Nano particle enters in to the plant can be stopped by the cell wall. The specific properties of the cell wall allowing the transport of Nano particles could be attributed to the pore size of the cell wall (Fleischer et al., 1999). The nano particles that are in the size range with in the cell wall pore size could effectively cross the cell wall and reach the plasma membrane. The rate of entry depends on the size and surface properties of nanoparticles. In deed the smaller nanoparticles can enter in to the plant cell easily. In contrast the larger nanoparticles being unable to enter the cells, cannot affect the cell metabolic pathway. Larger nanoparticles can penetrate the cell hydathodes, flower stigmas and stomata. Mechanism of interaction between nanoparticles and plant could be chemical or physical. Chemical interactions involve the production of reactive oxygen species, disturbance of ion cell, membrane transport activity, oxidative damage and lipid per oxidation. Following entry into the plant cells, Nanoparticles after mixing behave as a metal ion and react with the sulfhydryl, carboxyl groups and ultimately alter the protein activity.

\section{Nanofertilizers and plant growth}

Nanoparticles interact with plants causing many morphological and physiological changes depending upon the properties of Nanoparticles.

The Nano particles delivered at safe dose may help in promoting plant growth and over all yield (Lopez Moreno et al., 2010).

\section{Nano particles and seed germination}

Nanoparticles significantly influenced the seed germination and seedling growth and seed vigour. Nano fertilizers can easily penetrate in to the seed and increase the availability of the nutrient to the growing seedling which results in to the healthy and more shoot length and root length but if the concentration is more than the optimum it may show the inhibitory effects on the germination and seedling growth of the plant.

\section{The interaction of water stress and nano- fertilizer}

All the nutrients in branches of plants increased at budding period while the uptake decreased at fruiting period by water deficit. Nutrients uptake in leaves followed the same response of that in branches except for $\mathrm{Fe}$ uptake that gave higher values with the deficit irrigation in comparison with that by the regular irrigation treatment. Under water stress condition, the uptake of $\mathrm{N}$ decreased in plants. This decline in shoot $\mathrm{N}$ uptake can be attributed to the decreased transpiration rate to transport $\mathrm{N}$ from roots to shoots.

The uptake of $\mathrm{N}, \mathrm{Na}, \mathrm{K}, \mathrm{Ca}, \mathrm{S}$ and $\mathrm{Mg}$ were significantly reduced by water stress. Further the Stress increased the content of organic acids and sugar which improved fruit quality. Decreasing in the nutrients uptake of crop plants under water stress mainly due to the decrease in transpiration rates, damage of the membrane permeability and active transport, resulting in reduce absorbance activity of the plant roots. In addition, the nutrients uptake from the soil is strongly related to the plant root system and soil water status. Low content of soil moisture reduces the diffusion rate of the nutrients to the absorbing surface of the root system. The changes in the soil moisture regime could alter the root morphology and anatomy, the pore size distribution, and the angle of roots penetration, which affect root proliferation. Further, the development of the root system linked with the water status of the plants. Under water stress condition, highest water uptake occurs at the young roots stage. 
With growing of the root and reduction of water availability, a decline of root activity mainly root permeability will take place, causing, disturbance in the root metabolism. Moreover, this condition declines the internal water content of the shoots and influence stomata opening, ultimately, affecting the transpiration and nutrients uptake processes.

Foliar application of Nano-fertilizer increased the uptake of nutrients in branches under different irrigation process. These were true also for nutrient uptake in leaves. This was might be due to the improvement of dry matter contents of both plant parts. The Nano fertilizer improved the content of nutrients and this intern reflects on the vegetative growth and fruiting of plants and finally the yield and quality.

\section{Review of literature}

Jinghua (2004) reported in his study that the application of Nano-composite consists of $\mathrm{N}$, $\mathrm{P}$ and $\mathrm{K}$ micronutrients, mannose and amino acids enhance the uptake and use of nutrients by the grain crops.

Tahir et al., (2010) reported that the silicon application significantly increased wheat biomass. Silicon nano particles at high concentration triggered a decrease in membrane resistance and by disturbing bio membrane integrity and photosynthesis apparatus.

Prasad et al., (2012) while studying the effect of Nano scale Zinc oxide particles on the Germination growth and yield of Peanut and revealed the response of groundnut on the lower dose of Nano scale Zinc oxide was highly significant. The dry pod yield of ground nut was greatly influenced by Nano scale Zinc. Significant increase in number of pods/plant, number of filled pods per plant and also plant height with the application of
Nano scale Zinc oxide at 2 g/15 litre. Further, $30.5 \%$ and $38.8 \%$ higher pod yield was recorded with the with the application of Nano scale $\mathrm{ZnO}$ at $2 \mathrm{~g} / 15$ litre +NPK compared to NPK alone and $29.5 \%$ and $26.3 \%$ higher pod yield compared to chelated Zinc at $30 \mathrm{~g} / 15$ litre +NPK also Foliar application of Nano scale $\mathrm{ZnO}$ at $2 \mathrm{~g} / 15$ litre significantly increased pod yield and shelling percentage. This might be due to the reason that $\mathrm{ZnO}$ in the Nano scale form is absorbed by the plant to a larger extent than $\mathrm{ZnSo}_{4}$. These particles are proved effective in enhancing plant growth, development and yield.

Tarafdar et al., (2012) in their study observed a significant increase in yield due to foliar application of Nano particles.640 mg/ha application of foliar application (40ppm concentration) of Nano phosphorus gave $80 \mathrm{~kg} / \mathrm{ha} \mathrm{P}$ equivalent yield of Cluster bean and pearl millet under arid environment.

Farnia et al., (2014) conducted field experiment at Iran to study the effect of Knano fertilizer on yield and yield components of red bean (Phaseolus vulgaris L.) and observed that

Significant difference in yield and yield attributes was recorded among the different treatments of $\mathrm{K}$ Chelate Nano-Fertilizer. Among the different treatments significantly highest number of grain/pod, 1000-grain weight $(\mathrm{g})$, biological yield $(\mathrm{kg} / \mathrm{ha})$, grain yield (kg/ha) and Harvest index (\%) was recorded with 2 in $1000 \mathrm{~K}$ coated Nano fertilizer (Foliar spray) whereas lowest number of grain/pod, 1000-grain weight $(\mathrm{g})$, biological yield $(\mathrm{kg} / \mathrm{ha})$, grain yield $(\mathrm{kg} / \mathrm{ha})$ and Harvest index (\%) was recorded with control. This was might be due to the reason that the Nano fertilizer might have helped the seed to stay healthier for longer time and subsequently produced more vigorous plant. 
Armin et al., (2014) conducted field experiment to study the effect of time and concentration of Nano-Fe foliar application on yield and yield components of wheat observed that Foliar application of Nano-Fe foliar spray at tillering +stem elongation and tillering had $9.17 \%$ and $5.19 \%$ more grain yield. Foliar application of $\mathrm{Fe}$ at $2 \%, 4 \%$ and $6 \%$ produced an increase of $12 \%, 22.09 \%$ and $19.07 \%$ grain yield over the control

Yuvraj and Subramanian (2014) conducted experiment at Tamil Nadu Agricultural University, Coimbatore India to study the Fabrication of Nano Zinc fertilizer on growth parameter of Rice and observed that under submerged soil condition, $\mathrm{Zn}$ fertilization done through $\mathrm{Zn}$ loaded Nano fertilizer and $\mathrm{ZnSo}_{4}$ had increased growth parameter such as plant height $(\mathrm{cm})$ and root length. This was might be due to the reason that the Nano fertilizer which was produced to improve slow releasing ability of fertilizer is a suitable alternative to conventional fertilizer to improve the $\mathrm{Zn}$ nutrient use efficiency.

Abdul et al., (2015) conducted experiment to determine the potential of copper Nanoparticles for enhancing growth the and yield of wheat and observed that addition of copper nanoparticles up to $0.4 \mathrm{ppm}$ significantly increased the leaf area, chlorophyll content, plant fresh weight, dry weight and root weight over control. Further increase in level of copper nanoparticles caused significant drop in value of the growth parameters except plant fresh weight that started decreasing at $0.8 \mathrm{ppm}$. This might be due to more bioavailability, absorption and accumulation of nanoparticles leading to toxic effect. The best results i.e., number of spikes/plant, 100-grain weight and grain yield per pot were achieved with the application of 30ppm copper nanoparticles. Declining trend in growth and yield at concentration than $30 \mathrm{ppm}$ might be due to due to the more absorption of nanoparticles leading to the toxic effects.

Bakhtiari et al., (2015) conducted field experiment at loamy sand soil of Iran to study the effect of Iron Nano particles spraying time and concentration on wheat and revealed that among the different concentration of iron Nano-oxide concentration the highest spike weight (g), 1000-grain weight (g), Biological yield ( $\mathrm{kg} / \mathrm{ha})$, Grain yield $(\mathrm{kg} / \mathrm{ha})$ and protein content (\%) was recorded with the $0.04 \%$ concentration whereas the lowest spike weight (g), 1000-grain weight (g), Biological yield $(\mathrm{kg} / \mathrm{ha})$, Grain yield $(\mathrm{kg} / \mathrm{ha})$ and protein content (\%) was recorded with Control.

Mosanna et al., (2015) while studying the effect of Zinc Nano- chelate foliar and soil application on Morpho-physiological characteristics of maize (Zea mays L.) and observed significant effect of Nano- Chelate $\mathrm{Zn}$ application on plant height, 100-grain weight $(\mathrm{g})$, seed yield and harvest index. The soil application of Nano-Chelate Zn had 67\% highest plant height and $53 \%$ higher grain yield whereas foliar application of NanoChelate $\mathrm{Zn}$ had $94 \%$ more seed yield per plant.

Hafiz et al., (2015), while studying the effect of silver nanoparticles on the growth and yield attributes of wheat observed that the silver nanoparticles@ @25ppm produced significantly greater number of grains/spike followed by $75 \mathrm{ppm}$. Significant difference was also recorded among the treatments for 100 grain weight. Significantly highest 100grain weight was recorded with the treatment $25 \mathrm{ppm}$ followed by 50ppm whereas significantly lowest 100-grain weight was recorded with $75 \mathrm{ppm}$. Silver nanoparticles increased the yield may be due to the growth, stimulating effect of the Silver (Sharon et al., 2010). 
Karimi and Mohsenzadeh (2016) while studying the effect of Nanoparticles on growth and Physiology of Wheat seedling observed that fresh and dry weight of wheat seedling shoots at 50 and $100 \mathrm{mg} \mathrm{SiO}_{2} / \mathrm{L}$ concentration didn't show significant changes with the control whereas 200, 400 and 800 $\mathrm{mg} / \mathrm{L}$ of $\mathrm{SiO}_{2}$ Nano particles, the weight of shoot significantly decreased. The increase in weight in 50 and $100 \mathrm{mg} / \mathrm{L}$ concentration might be due to the reason that silver oxide nanoparticles facilitated the water uptake and transportation in to the plants. This beneficial effect of silicon oxide might be due to its hydrophilicity.

Jyothi et al., (2017) while studying the effect of Nano fertilizers on the growth and yield of selected cereals observed that the full recommended rate of conventional dose Nano fertilizers (FRR-CF+FRR-NF) enhanced the plant height, chlorophyll content, number of reproductive tillers, panicles and spikelet's in rice.

\section{References}

Adhikari, Tapan, Biswas AK and Kundu S. 2010. Nanofertilizer -a new simension in Agriculture. Indian Journal of fertility 6: 22-24.

Armin, M., Akbari, S. and Mashhadi, S. 2014. Effect of time and concentration of nano-Fe foliar application on yield and yield components of Wheat. International Journal of Biosciences. 4(9): 69-75.

Bakhtiari, M., Moaveni, P. and Saini, B. 2015. The effect of Iron Nanoparticles spraying time and concentration on Wheat. Biological Forum - An International Journal. 7(1): 679-683.

Brady, NR. and Weil, R.R. 1999. In: Brady NR, Weil RR (eds). The nature and properties of soils. Prentice Hall, New Jersey, pp-415-473.
Brunnert, I., Wick, P., Manserp., Spohnp., Grass, R.N., Limbach, L.K., Bruinink, A. and Stark, W.J. 2006. Environmental Science and Technology. 40: 43744381.

Chinnamuthu, CR. and Boopati, PM. 2009. Nanotechnology and Agro ecosystem. Madras Agricultural Journal. 96: 1731.

Chinnamuttu, C.R. and Kokiladevi E. 2007. Weed management through Nanoherbicides. In: Application of nanotechnology in agriculture.

Corradini, E, De Moura, M.R., Mattosa LHC 2010. Applications of nanotechnology in agrochemical formulations, perspectives, challenges and strategies. In: International conference on Nanoagri, Sao Pedro, Brazil, pp-28-33.

Cui, H.X., Sun, C.J., Liu, Q., Jing, J. and Gu W. 2010. Applications of nanotechnology in agrochemical formulations, perspectives, challenges and strategies. In: International Conference on Nanoagri, Sao Pedro, Brazil, pp-28-33.

EPA (2007). Nanotechnolgy White paper.US Environmental protection agency report, EPA100/B-07/001, Washington DC 20460, USA.

Farina, A and Ghorbani, A. 2014. Effect of K Nano-fertilizer and $\mathrm{N}$ - bio fertilizer on yield and yield components of Red bean (Phaseolus Vulgaris L.). International Journal of Biosciences. 5(12): 296-303.

Fleischer, A., O, Neill, M.A., and Ehwald, R. The pore size of non-graminaceous plant cell walls is rapidly decreased by borate ester cross linking of the pectic polysaccharide rhamnogalacturonan II. Plant physiology, 121-829-838.

Gericke, W.F. 1937. Hydroponics -crop production in liquid culture media in liquid culture media. Science. 85:177178.

Ghormade, V., Deshpande, MV. and Pakinar, 
K.M. 2011. Perspectives for Nanobiotechnology enabled protection and nutrition of plants. Biotechnol Adv 29: 792-803.

Hafeez, M.J., Razzaq, A., Jilani, G., Rehman, A., Hafeez, A. and Yassen, F. 2015. Silver nanoparticles enhance the growth, yield and nutrient use efficiency of Wheat. International Journal of Agronomy Agricultural Research, 7(1): $15-22$.

Hafeez, A., Razzak, A., Mahmood, T and Jhanzab, H.M., 2015. Potentional of copper Nanoparticles to increase growth and yield of Wheat. Journal of Nano science with advance technology, 1(2): 6-11.

Hussien, M.M., Ashry, S.M., Haggag, W.M and Mubarak, D.M. 2015. Response of Mineral Status to Nano-Fertilizer and Moisture Stress during Different Growth Stages of Cotton Plants. International Journal of Chem Tech Research. 8(12): 643-650.

Jinghua, G. 2004. Synchrotron radiation, so $\mathrm{X}$-ray spectroscopy and nano-materials. Journal of Nanotechnology, 1: 193-225.

Jyothi, T.V and Hebsur, N.S. 2017. Effect of Nanofertilizers on growth and yield of selected cereals. Agricultural Reviews. 38(2): 112-120.

Karimi, J. and Mohsenzadeh, S. 2016.Effect of silicon oxide Nanoparticles on growth and Physiology of Wheat seedlings. Russian Journal of Plant Physiology. 63(1): 119-123.

Kottegada, N., Munawerra, I., Madusanka, N., Karunaratne, V., 2011. A green slow release fertilizer composition based on Urea-modified hydroxyapatite nano particles encapsulated wood. Current Science. 101: 73-78.

Lopez-Moreno, M.L., De La Rosa G., Veizcas, H., Castillio-Mischel, H., Botez, CE., Peralta Videa, J.R., GardeaTorresdey JL. 2010. Evidence of the differential transformation and geno toxicity of $\mathrm{ZnO}$ and $\mathrm{CeO}_{2}$ Nanoparticles on soya bean (Glycine Max) plants. Environ Sci Technol., 44: 7315-7320.

Milani, N., McLaughlin, M.J, Stacey, SP., Kirkyby, J.K., Hettiarachchi, G.M., Break, D.G., Cornelis, G. 2012. Dissolution kinetics of macronutrient fertilizers coated with manufactured Zinc oxide Nanoparticles. J Agric Food Chem., 60: 3991-3998.

Mir, S., Sirousmehr, A., Shirmohammadi, E. 2015. Effect of Nano and biological fertilizers on carbohydrate and chlorophyll content of Forage sorghum (Speed feed hybrid), International Journal of Biosciences, 6(4): 157-164.

Miransari, M. (2011). Soil microbes and plant fertilization. Applied Microbiological Biotechnol., 92: 875-885.

Monsef-Afshar R, Hadi H, Pirzad A.2013. Effect of Nano-iron on the yield and yield component of Cowpea under end season water deficit. International Journal of Agricultural., 3(1): 27-34.

Mosanna, R and Behrozyar, E.K. 2015. Morpho-physiological response of maize (Zea mays L.) to Zinc Nanochelate foliar and soil application at different growth stages. Journal of New Biological Reports, 4(1): 46-50.

Naderi, M.R., Danesh Shahraki. 2013. Nano fertilizers and their roles in sustainable Agriculture. A International Journal of Agriculture and crop Sciences, 5(19): 2229-2232.

Nandi, E., Aynehband, A., Mojaddam, M. 2013. Effect of Nano-iron chelate fertilizer on grain yield, protein percent and chlorophyll content of Faba bean (Vicia faba L.). International Journal of Biosciences, 3(9): 267-272.

Nel A., Xia T., Madlerl and Li N. 2006. Science, 311, 622-627.

Ombodi, A. and Saigusa M. (2000). Broadcast application versus band 
application of polyolefin-coated fertilizer on green peppers grown on andisol. Journal of Plant nutrition. 23:1485-1493.

Prasad, T.N., V.K.V., Sudhakar, P., Sreeenivasulu, Y., Latha, P., Munaswamy, V., Reddy, K.R., Sreeprasad, T.S., Sajanlal, P.R. and Pradeep, T. 2012. Effect of Nano scale Zinc Oxide particles on the germination growth and yield of Peanut. Journal of Plant Nutrition, 35(6): 905-927.

Sasson, Y., Levy-Ruso G, Tolendano, O. and Ishaaya, I. 2007. Nanosuspensions: emerging novel agrochemical formulations. In: Ishaaya, I Horowitz AR, Nauen R (eds). Insecticides design using advanced technologies. Springer, Berlin, pp-1-39.

Sharon, M., Choudhary, A. and Kumar, R. 2010. Nanotechnology in Agriculture disease and Food safety. Journal of Phytologist, 2(4):83-92.

Silva M.S., Cocenza D.S., Grillo R., Melo N.F.S., Tonello P.S., Oliveira L.C., Cassimiro D.L., Rosa A.H and Fraceto L.F. 2011. J Hazardous Materials, 190 (1-3), 366-374.

Singh, M.D., Chirag, G., Prakash, P.O., Mohan, M.H., Prakasha, G. and Vishwajith. 2017. Nanofertilizers is a new way to increase Nutrient efficiency in crop production. International Journal of Agricultural Sciences. 9(7): 3831-3833.

T.V. Jyothi and Hebsur, N.S. 2017.Effect of Nano fertilizers on growth and yield of selected cereals. Agricultural Reviews. 38(2): 112-120.
Tahir, M.A., Rahmatullah, A., Aziz, T., and Ashraf, M. 2010. Wheat genotypes differed significantly in their response to silicon nutrition under salinity stress. Journal of Plant Nutrition. 33, pp. 1658-1671.

Taiz, L., Zeiger E. 2010. Plant physiology, $5^{\text {th }}$ edn. Sinauer Associates Inc., Massaschusetts, 781pp.

Tarafdar, J.C. 2012. Perspectives of Nano technological applications for crop production. NAAS News, 12, 8-11.

Tarafdar, J.C., Raliya, R. and Rathore, I. 2012. Microbial synthesis of phosphorus nanoparticles from Tricalcium phosphate using Aspergillus tubingensis TFR-5. Journal of Bionanoscience 6, 84-89.

Tilman, D., Knops, J., Wedin, D., and Reich, P. 2002. Plant diversity and composition: effects on productivity and nutrient and dynamics of experimental grasslands. In: Loreau M, Naeem S, Inchausti $\mathrm{P}$ (Eds), Biodiversity and ecosystem functioning. Oxford University press, Oxford, pp: 21-35.

Torney, F., Trewyn, B.G, Lin, V.S.Y, Wang, K. 2007. Mesoporous silica nano particles deliver DNA and chemical in to plants. Nat Nanotechnol., 2:295-300.

Weathers, P.J., Zobel, R.W. 1992. Aeroponics for the culture of organisms, tissues and cells. Biotechnology Adv., 10: 93-115.

Yuvaraj, M and Subramanian. 2014. Fabrication of Zinc Nano Fertilizer on Growth parameter of Rice. Trends in Biosciences. 7(1): 2564-2565.

\section{How to cite this article:}

Sunil Kumar, I.J. Gulati, S.R. Yadav, Manisha, P.C. Moharana, R.L. Meena, M. Nogiya and Singh, R.S. 2017. Assessing of Potassium Reserve and their Relationship with Soil Properties in Western Plain of Arid India. Int.J.Curr.Microbiol.App.Sci. 6(12): 1541-1551. doi: https://doi.org/10.20546/ijcmas.2017.612.172 